\title{
O TRABALHO ESCRAVO DOS MADEIREIROS FRENTE ÀS NOVAS LEGISLAÇÕES
}

\section{Leda Maria Messias da Silva ${ }^{1}$ Leandra Cauneto Alvão ${ }^{2}$}

\begin{abstract}
RESUMO: O presente artigo faz um breve histórico sobre o trabalho escravo contemporâneo e as novas legislações relatando suas características. Coloca, de forma concisa, qual o perfil da pessoa que é submetida à situação análoga à escravidão. Igualmente, conduz informações recentes sobre o trabalho dos madeireiros, que, geralmente, são pessoas humildes e acabam caindo nas mãos de grileiros. Aborda, ainda, as consequências do trabalho escravo com relação às lesões aos direitos da personalidade e produz uma análise sobre alguns projetos de lei, que, caso sejam aprovados, representam enorme retrocesso social. Trata-se de pesquisa teórica, na qual empregou-se, principalmente, o método dedutivo.
\end{abstract}

PALAVRAS-CHAVE: Trabalho Escravo; Madeireiros; Direitos da Personalidade; Projeto de lei; Retrocesso Social.

\section{THE LABOR SHAVE OF THE WOODWORKS IN FRONT OF THE NEW LEGISLATIONS}

\begin{abstract}
This article gives a brief history about contemporary slave labor and new legislation reporting its characteristics. It puts, in a concise way, the profile of the person who is subjected to the situation analogous to slavery. It also carries recent information on the work of loggers, who are usually humble people and end up falling into the hands of illegal forest deforestation. It also deals with the consequences of slave labor in relation to injuries to the rights of the personality and produces an analysis on some bills, which, if approved, represent a huge social setback. It is a theoretical research, in which the deductive method was mainly used.
\end{abstract}

KEY WORDS: Slavery; Timber Merchants; Rights of the Personality; Bill of Rights; Social Retraction.

\footnotetext{
${ }^{1}$ Pós-doutora em Direito do Trabalho, pela Universidade de Lisboa; Doutora e Mestre em Direito do Trabalho, pela PUC-SP; Professora do Mestrado em Ciências Jurídicas do Centro Universitário de Maringá-PR (UNICESUMAR) e da Pós-graduação e graduação da Universidade Estadual de Maringá-PR; ex professora da Universidade Cândido Mendes (UCAM), no Rio de Janeiro-RJ; pesquisadora do ICETI/UNICESUMAR em Grupo de Pesquisa junto ao CNPQ; endereço eletrônico: lemead @uol.com.br.

${ }^{2}$ Mestranda em Ciências Jurídicas do Centro Universitário de Maringá-PR (UNICESUMAR); Juíza Leiga no Tribunal de Justiça do Paraná; Advogada; Especialista em Direito do Trabalho e Processual do Trabalho, pela Universidade São Judas Tadeu-SP (USJT); Especialista em Métodos e Técnicas de Ensino, pela Universidade Tecnológica Federal do Paraná (UTFPR); pesquisadora dos Direitos da Personalidade e seu Alcance na Contemporaneidade; endereço eletrônico: leandra.alvao@gmail.com.
} 


\section{INTRODUÇÃO}

Para os dias atuais, a questão em torno do trabalho escravo contemporâneo, num primeiro momento, pode parecer conteúdo desatualizado ou, mesmo, uma realidade inverídica; entretanto, recorrendo a pesquisas e documentos oficiais do Ministério Público do Trabalho (MPT) e de outros órgãos, assim como explorando reportagens investigativas sobre o assunto, é possível verificar que este é um problema plenamente vigente, que se precipita quase sem óbice, e infelizmente, em todo o território nacional.

As pessoas submetidas ao trabalho escravo moderno são, predominantemente, humildes, com parcos recursos. Dessa forma, aceitam as condições ínfimas para sobreviverem, sobretudo, pela precariedade de onde residem, pois lhes faltam infraestrutura, qualificação de mão de obra, além de desenvolvimento econômico e social na região.

Essas situações insalubres se repetem em âmbito nacional e seu combate, em favor de um mínimo de dignidade humana, deve ser permanente. Mesmo assim, não raro, pelo fato de os locais serem de difícil acesso, a fiscalização segue sendo morosa e, quando ali chega, muitas vezes, por conta da precariedade e da necessidade de manter o sustento, as pessoas preferem fugir e continuar na condição statu qua nom a confiar nos fiscais.

Tal cenário, por um lado, revela, portanto, o quanto ainda é imperativo seguir com a vigilância nos mais diferentes e distantes rincões do país. Já por outro, denuncia, fundamentalmente, uma situação que fere, de modo direto, aos direitos da personalidade daqueles que sofrem nas mãos de grileiros e fazendeiros de grande porte nessas áreas; são pessoas, trabalhadores, que não recebem salário fixo, são explorados pelos empregadores e coagidos a não se manifestarem junto aos órgãos competentes, elementos que configuram grave desobediência às normas trabalhistas e, mormente, às questões humanitárias.

Apesar de o Brasil ter sido reconhecido mundialmente como o país com uma das legislações mais modernas nessa matéria, o que vemos no quadro presente é um caminho que pode nos levar para o retrocesso social, pois tramitam, no Congresso Nacional, projetos de leis que tencionam a retirada de direitos que foram adquiridos, com muito sacrifício, ao longo dos anos.

Com isso, é preciso que o Governo Federal e os órgãos responsáveis pela fiscalização e prevenção do trabalho escravo tenham postura combativa quanto ao dilema da escravidão moderna; seus vieses permeiam um horizonte insustentável, vergonhoso, que infringem os 
direitos da personalidade e a dignidade humana. E a proteção desses direitos constitui objeto que deve receber total atenção e cuidado, o que por si justifica a proposta deste artigo.

Para tanto, foi empregado o método dedutivo, que extrai conclusões a partir do geral para o particular. A pesquisa é qualitativa e teórica, tendo como instrumentos, principalmente, livros, periódicos científicos e documentos disponíveis na Internet.

\section{TRABALHO ESCRAVO CONTEMPORÂNEO: CONCEITO DOUTRINÁRIO E LEGAL}

Conforme constata Vito Palo Neto (2008, p. 70), no relatório global publicado em 2005, ao comparar trabalho forçado e escravidão, definiu-se que "[...] a escravidão é uma forma de trabalho forçado que implica o controle absoluto de uma pessoa por outra ou, em outras ocasiões, um grupo social por outro".

A terminologia sobre trabalho escravo pode variar, assim, esclarece José Claudio Monteiro de Brito Filho (2017, p. 40), condições análogas à de escravo, ou, simplesmente, trabalho escravo, e trabalho forçado, que é a denominação utilizada pela Organização Internacional do Trabalho são expressões com o mesmo significado.

Para Juliano Chaves Cortez (2015, p. 18), trabalho em condições análogas a escravo “[...] compreende não apenas o trabalho forçado, atrelado à restrição da liberdade, mas também o trabalho degradante, com restrições à autodeterminação do trabalhador”.

Nas palavras de Luciana Aparecida Lotto (2015, p. 35), trabalho contemporâneo ou forçado é:

toda modalidade de exploração do trabalho em que esteja impedido, moral, psicológica e/ou fisicamente, de abandonar o serviço, no momento e pelas razões que entender apropriadas, a despeito de haver, inicialmente, ajustado livremente a prestação de serviços.

A Organização Internacional do Trabalho, através da Convenção n. 29 prevê: "'trabalho forçado ou obrigatório é todo trabalho ou serviço exigido de um indivíduo sob ameaça de sanção e para o qual não se tenha oferecido espontaneamente”.

No Brasil, o trabalho escravo está previsto como crime, conforme o art. 149 do Código Penal (Decreto-Lei n ${ }^{\circ}$ 2.848/1940). Para ser caracterizado enquanto tal, faz-se necessário que o trabalhador esteja atuando em, ao menos, uma das seguintes condições: 
1) Trabalho forçado: o trabalhador é obrigado a permanecer no local onde é explorado e não há possibilidade de sair, seja por dívidas, seja por ameaças físicas e/ou psicológica;

2) Jornada exaustiva: expediente extenuante que coloca em risco a vida do trabalhador, perfazendo horas extras sem a justa remuneração. Com intervalos restritos e insuficientes para o condigno descanso, tão necessário para repor a energia, além de desrespeito ao repouso semanal, gerando, assim, o impedimento da vida social e familiar do trabalhador;

3) Servidão por dívida: o trabalhador é mantido no local por meio de dívidas que nunca se findam, pois, a cobrança de materiais de trabalho, transporte, alimentação, entre outros, é abusiva;

4) Condição degradante: precariedade do trabalho e das condições de vida, o que desrespeita a dignidade do trabalhador (BRASIL, 2011).

Legalmente, a escravidão, no Brasil, foi abolida em 1888, com a Lei Áurea. No entanto, em países em que a democracia ainda é recente ou frágil, seja devido à própria legislação ou por falta de fiscalização adequada, segue sendo possível confirmar que esse ponto tão controverso da história dos povos persiste vigorosamente.

De 1995 a 2014, foram resgatados, aproximadamente, 47 mil trabalhadores que atuavam em diversas áreas da atividade econômica, em todo território nacional; espaços notadamente desenvolvidos, na zona rural, com atividades como pecuária, produção de carvão e cultivos de cana-de-açúcar, soja e algodão, bem como na indústria da madeira, que será o tema central deste artigo "Trabalho Escravo dos Madeireiros Frente às Novas Legislações".

\subsection{O PERFIL DO ESCRAVO CONTEMPORÂNEO}

Os trabalhadores encontrados em situação de escravidão, na quase totalidade, são extremamente desprovidos e, por isso, aceitam o serviço, quase sempre, enganados, ainda que estejam em busca de melhores condições de vida para si e suas famílias. Em sua maioria, são homens $(95,0 \%)$, pois as atividades exigem excessiva força braçal; pelo tipo de trabalho desenvolvido, apesar de se haver registros também nos centros urbanos, a maior incidência dos casos acontece no campo, razão pela qual os aliciadores procuram homens e jovens. Outro dado relevante é que cerca de 72,10\% desses não têm escolaridade ou não concluíram o quinto ano do ensino fundamental (SUZUKI; CASTELI, 2016).

Em muitas circunstâncias, os obreiros conseguem fugir e procuram os órgãos competentes para formalizar sua denúncia, porém são obrigados a retornarem para a mesma 
comunidade de onde saíram, local em que, geralmente, não existe estrutura para realocá-los e, assim, voltam e continuam nas mãos dos aliciadores. Eis o chamado Ciclo do Trabalho Escravo.

E para que esse ciclo não se perpetue, é inevitável a atuação constante do Estado, por meio de políticas públicas para a conscientização quanto ao problema, com a orientação sobre onde ir para fazer as queixas, sendo identicamente urgente que essas pessoas tenham condições de vida diferentes, com melhores empregos e qualificação profissional.

Nesse sentido, há nítida dependência da vontade política, todavia, o que vemos no enquadramento atual são projetos de leis que apontam para a diminuição das garantias legais a respeito do tema, visto que o hodierno Congresso Nacional é caracterizado como o mais conservador, desde a época da ditadura militar de 1964. Ainda sobre o Congresso, aliás, este se encontra, notadamente, composto, em sua maioria, por três bancadas: 1) a bancada da Bala, políticos que foram financiados pela indústria de armas e munições; 2) a bancada da Bíblia, os evangélicos conservadores; e 3) a bancada do Boi, políticos vinculados ao agronegócio. Em suma: caricatamente, a bancada BBB (MEDEIROS; FONSECA, 2016).

Conforme mencionaram Benizete Ramos de Medeiros e Ellen Hazan "nem todos os direitos mínimos do trabalhador são concretizados, apesar de existirem formalmente no Brasil. Em se tratando de escravidão contemporânea nenhum direito é respeitado" (2017, p. 141).

Diante desse panorama, percebe-se o quão facilmente, os direitos da personalidade dos trabalhadores madeireiros e dos demais trabalhadores, caminham cada vez mais para a vulnerabilidade.

\section{O TRABALHO ESCRAVO DOS MADEIREIROS E SUAS CONSEQUENCIAS NOS DIREITOS DA PERSONALIDADE}

Os direitos da personalidade visam garantir a dignidade da pessoa humana. A Constituição Federal (artigo 5º inciso V e X) e o Código Civil (artigos 11 ao 21) elencam rol exemplificativo.

Para Julpiano Chaves Cortez (2015, p. 14), “[...] trabalho escravo ou trabalho em condição análoga a de escravo agride os direitos da personalidade, também denominados de direitos fundamentais, violando bem jurídico a ser protegido, que é a dignidade da pessoa humana". 
Celso Antônio Pacheco Fiorillo (2012, p. 33) afirma que a dignidade da pessoa humana deve ser estabelecida como "piso" de política de desenvolvimento, além de projetar e assegurar todos os demais direitos na sociedade previstos na Constituição Federal.

Ademais, a Constituição Federal, em seu art. 170, estabelece: “A ordem econômica, fundada na valorização do trabalho humano e na livre iniciativa, tem por fim assegurar a todos existência digna, conforme os ditames da justiça social, observado como princípios [...] VI - a defesa do meio ambiente" (BRASIL, 1988).

Por outro turno, as professoras Leda Maria Messias da Silva e Marice Taques Pereira (2013, p 47) sublinham que:

[...] o objetivo da determinação de normas de direitos humanos no ambiente de trabalho é justamente para manter a ideia de que o homem não é feito para o trabalho e sim o contrário, o trabalhador tem o direito de ser tratado com dignidade e não como um objeto de produção. Deve-se buscar uma forma de segurança para o trabalhador no ambiente laboral quanto às diversas maneiras existentes neste local de degradação de sua sadia qualidade de vida, tanto no aspecto físico como psíquico.

Assim, Pablo Stolze Gagliano e Rodolfo Pamplona Filho (2013, p. 183), entendem que “[...] o homem não deve ser protegido somente em seu patrimônio, mas sim, principalmente, em sua essência".

Celso Antônio Pacheco Fiorillo e Christiany Pegorari Conte (2013, p. 38) expressam semelhante raciocínio ao afirmarem que o direito à dignidade, como princípio constitucional, impõe a defesa da integridade física e espiritual do homem como dimensão inalienável da sua individualidade, pelo livre desenvolvimento da personalidade.

Segundo Mauricio Godinho Delgado (2013, p. 38), o princípio da dignidade da pessoa humana traduz a ideia de que o valor das sociedades, do Direito e do Estado contemporâneo é a pessoa humana, em sua singeleza, independente de seu status econômico, social ou intelectual.

Dito isso, Kevin Bales, cofundador da organização Free the Slaves, especialista em trabalho escravo, professor de direitos humanos e titular da disciplina Escravidão Contemporânea, na Universidade de Nottingham, na Inglaterra, assevera que: “[...] a questão central é como alguns grupos estão operando ilegalmente. As pessoas são submetidas a um controle violento em florestas que supostamente estão protegidas”.

Avançando a questão adstrita à realidade brasileira, os donos das serrarias ilegais buscam o menor custo possível para o seu comércio de madeira, como acontece com qualquer outro recurso que seja passível de exploração, e ficam protegidos pela ilicitude e pela falta de 
fiscalização. Os produtos derivados da ilegalidade são vendidos o mais longe possível, o que não deixa pistas de sua origem. Mesmo sendo crimes praticados por pequenos operadores, as grandes empresas acabam se beneficiando da extração ilegal, pois, devido ao não pagamento de impostos, desembolsam valores menores em madeiras de lei, que, supostamente, deveriam estar protegidas do abate.

Nessa mesma linha de raciocínio, Neto Palo (2008, p. 96), observa que:

o trabalho escravo "[...] não se limita à infração de questões trabalhistas, mas é uma grave violação de direitos humanos e, são acompanhados de outros crimes como crimes ambientais, grilagem de terra, falsificações de documentos, além de lesões corporais e até assassinatos".

Já Bales, destaca ainda que, a destruição ambiental e a escravidão moderna estão intrinsecamente ligadas, já que vulnerabiliza as pessoas.

A destruição ambiental cria uma vulnerabilidade enorme, principalmente quando pensamos em pessoas que vivem em harmonia com o meio ambiente, aquelas que trabalham na agricultura, moram no litoral e vivem em lugares onde as mudanças climáticas e a destruição ambiental literalmente arrancam a terra debaixo dos seus pés. A terra desaparece literalmente, sob o aumento do nível do mar, ou por causa de erosão e desmatamento. Há os projetos de construção de hidrelétricas, e os pobres que moram na região são forçados a sair. Isso tudo gera muita vulnerabilidade. Eles são pobres, não têm onde morar, alguns são refugiados. Cria-se um contexto em que as pessoas podem ser escravizadas (ARANHA: DIAZ, 2017).

Palo Neto (2008, p. 97), frisa que, é bastante comum, principalmente na região amazônica, a derrubada da floresta em área grilada e o contrabando da madeira.

Um dos grandes obstáculos em relação à extração irregular da madeira e ao controle sobre a ilegalidade no trabalho escravo está no envolvimento de grandes empresas, tanto nacionais como internacionais, porque muitas delas não disponibilizam as informações necessárias para o consumidor conhecer a origem do produto.

É uma área muito difícil para policiar e para pesquisar. Muitas vezes, os criminosos se escondem atrás de "laranjas". Mesmo as pessoas que estão inspecionando cadeias de abastecimento que vão ter dificuldades de penetrar até o nível inferior. E quando os criminosos são expostos, eles passam para uma cadeia de abastecimento diferente. Então é uma questão de vigilância constante (PALO NETO, 2008, p. 97). 
Tal fato se deu com a marca Tramontina, que comprou madeira ilegal, proveniente de serraria flagrada com trabalho escravo contemporâneo. A fábrica, por sua vez, abastece lojas como Walmart do Brasil, Carrefour, Grupo Pão de Açúcar, Ponto Frio, Casas Bahia, Extra.com, entre outras. De acordo com a reportagem investigativa de André Campos, da ONG Repórter Brasil, grupos estrangeiros também compram madeira ilegal, resultante de trabalho escravo, e, assim, controversamente, acabam por financiar e sedimentar a prática no Brasil (CAMPOS, 2017).

\begin{abstract}
A mesma realidade foi detectada em exportadores que compraram de serrarias amazônicas responsabilizadas por submeter trabalhadores a condições análogas às de escravo. Elas vendem madeira para empresas como a US FLoors, que abastece a rede de materiais para construção norte-americana Lowe's. Outro comprador é a Timber Holdings, que já forneceu madeira para obras no Central Park e na Brooklyn Bridge. Tanto a US Floors quanto a Timber Holdings, procuradas pela reportagem, disseram que a madeira comprada por eles não é a mesma envolvida no flagrante de trabalho escravo. [...] Embora a reportagem não possa traçar o destino exato de cada pedaço de madeira, pois os produtos se misturam nos vendedores intermediários, a investigação revela que a rede de fornecedores de grandes grupos varejistas e da construção civil está contaminada pela prática criminosa. Ou seja, essas marcas estão financiando redes que exploram o trabalho escravo (2017).
\end{abstract}

A reportagem citada, menciona que, quando a fiscalização consegue chegar a esses locais, constata-se que os donos das serrarias ordenam que os trabalhadores fujam pela mata fechada para se esconderem. Tais trabalhadores, então, por receio de serem assassinados, obedecem às ordens recebidas. Consequentemente, o resgate se torna difícil, acarretando, outrossim, em dificuldade para punir os empregadores, ficando, mais uma vez, evidenciada a urgência em termos de maior fiscalização e compromisso por parte do Estado brasileiro no combate ao trabalho escravo contemporâneo. 


\section{PROJETOS DE LEI QUE TRAMITAM PARA APROVAÇÃO NO SENADO E NA CÂMARA FEDERAL E SUAS CONSEQUÊNCIAS NO MEIO AMBIENTE DE TRABALHO}

\subsection{PROJETO DE LEI Nº 432/2013}

Está em trâmite no Senado Federal o Projeto de Lei no 432/2013. Tal proposta normativa recebeu crítica contundente da Câmara Criminal do Ministério Público Federal (2CCR/MPF), pois, caso venha a ser aprovada enquanto norma, fragilizará a relação de trabalho e alterará as características que definem o trabalho escravo atualmente.

O Projeto tem como objetivo regulamentar a Emenda Constitucional $n^{\circ} 81$, que prevê a expropriação de imóveis que se utilizem de trabalho escravo e o confisco de bens de valor que foram produzidos pela exploração de mão de obra escrava.

O documento em tramitação quer excluir duas peculiaridades do trabalho escravo previstas no art. 149 do Código Penal Brasileiro: 1) a jornada exaustiva e 2) as condições degradantes de trabalho. Dessa forma, para ser considerado trabalho escravo, haveria apenas duas suposições, quais sejam: 1) trabalho forçado e 2) servidão por dívidas, ambas relacionadas somente mediante a privação de liberdade. Ou seja, uma vez aprovado o teor em análise, apenas sob a hipótese de o trabalhador estar privado de sua liberdade seria abalizado como trabalho escravo.

Nesse sentido, o MPF e a Câmara Criminal acreditam que tais possibilidades significam retrocesso social, já que o trabalho escravo voltaria a ser classificado segundo o seu conceito original.

No que se refere à expropriação do imóvel flagrado com trabalhador escravo, o MPF indica que, se sancionado o Projeto, o proprietário do imóvel poderá ser condenado, porém não haverá punição efetiva para outros envolvidos na ilegalidade praticada.

$\mathrm{O}$ art. $2^{\circ}$ do PL também determina que o proprietário deve ser penalizado apenas se estiver diretamente ligado ao trabalho análogo à escravidão. Entretanto, de acordo com as investigações e denúncias do MPF, os empregadores sempre têm uma pessoa intermediária na função de aliciar e manter os obreiros nos locais indicados, conservando-se, assim, sem contato direto com a situação real e, por esse motivo, muitas vezes, os trabalhadores sequer sabem ao certo para quem estão trabalhando. 
A nota atesta, ainda, que exigir a exploração direta de mão de obra escrava seria o mesmo que "[...] ceifar a eficácia repressiva da norma penal. Não haveria expropriação de terras usadas para o trabalho escravo e acabaria qualquer eficácia do art. 243 da Constituição Federal" (CAMPOS, 2017, p. 8).

Ou seja, mesmo condenado pela ilegalidade em manter trabalhadores escravos, o proprietário das terras não terá punição alguma perante a sociedade e, então, poderá continuar explorando trabalhadores e lucrando com isso, enriquecendo às custas de vulneráveis, devido à situação de miserabilidade sob as quais tais pessoas vivem.

A encontro dos esclarecimentos do MPF, a Organização das Nações Unidas (ONU) também divulgou um comunicado em que reprova essa tentativa de reduzir as hipóteses que caracterizam o trabalho escravo no Brasil, pois “[...] situações em que trabalhadores são submetidos a condições degradantes ou jornadas exaustivas, maculando frontalmente sua dignidade, ficariam impunes caso essa alteração legislativa seja aprovada" (ONUBR, 2016).

Rodrigo Garcia Schwarz (2014, p. 16) sustenta que as autoridades públicas adotem medidas contraditórias e pontua que "a luta contra o trabalho escravo contemporâneo tem sido marcada pela impunidade dos senhores rurais e pela manutenção do latifúndio”.

O Projeto em pauta demonstra, pois, haver interesses não necessariamente prótrabalhadores, mas uma pretensão ostensiva de beneficiar a exploração de pessoas miseráveis, sem o mínimo de assistência do Estado e, por esse motivo, obrigadas a recorrerem a trabalhos humilhantes, correndo o risco, principalmente, de morte. Por outro lado, beneficia aqueles que lucram com a miséria alheia, mas o pior é que, ao que tudo indica, que esses empregadores criminosos acabam tendo ajuda do próprio Estado brasileiro, caso tal projeto seja aprovado.

\subsection{MEDIDA PROVISÓRIA No 759/2016}

Em 25/05/2017, foi aprovada, pelo Senado Federal, a Medida Provisória no 759/2016, colimando a regularização fundiária, tanto na área urbana como na área rural.

Segundo Sergio Sauer, professor do programa de pós-graduação em Meio Ambiente e Desenvolvimento Rural da Universidade de Brasília (UnB), essa decisão, agora transformada em lei, encaminha severas alterações nas políticas públicas direcionadas ao acesso à terra, bem como à cidade (CAMPELO, 2017). Para ele, por meio dessa medida provisória, inicia-se uma mudança profunda no setor rural, de forma negativa, sobretudo para os mais pobres. Em outras 
palavras: essa medida é capaz de expropriar a população pobre do campo, uma vez que ela autoriza a regularização de terras por terceiros.

Pela ponderação do professor, na prática, o que poderá acontecer com a população rural é, de fato, um retrocesso, deixando de se cumprir a reforma agrária, fazendo com que ocorra desenvolvimento econômico sem se atentar aos cuidados necessários quanto aos pequenos produtores, levando à expropriação da população rural pobre.

Com isso, caso a nova lei tenha realmente tais efeitos, é possível deduzir que o trabalhador rural, sem suas terras para trabalhar e se sustentar, ficará, mais uma vez, à mercê da própria sorte, de modo que as situações de trabalho escravo apenas tendem a aumentar em meio à fragilizada parcela da população, mormente entre aqueles que se encontram nos confins do país, em locais de difícil acesso, acentuando o alarmante quadro que já se configura atualmente no país.

\subsection{PROJETO DE LEI N 6442/2016 - A LEGALIZAÇÃO DO TRABALHO ESCRAVO CONTEMPORÂNEO NO BRASIL}

O Projeto de Lei ${ }^{\circ} 6442 / 2016^{3}$ preocupa a população rural, bem como juristas que analisam a questão.

Em seu art. $3^{\circ}$, existe previsão do pagamento por qualquer espécie. Ou seja, se um empregador vier a efetuar o pagamento de seus funcionários convertido em comida e moradia, isso não mais será visto como infração às normas trabalhistas. A remuneração também poderá ser composta por parte da produção e concessão de terras.

Prevê, ainda, o art. $5^{\circ}$ que o trabalhador que reside no local do trabalho poderá vender suas férias integralmente, sempre a critério de aprovação do empregador. Além disso, o PL pressupõe, em seu art. $7^{\circ}, \S 2^{\circ}$, que o trabalhador rural poderá trabalhar até 12 horas diárias. Na prática, esse artigo coloca o trabalhador em jornada de trabalho extenuante, pois o PL não define

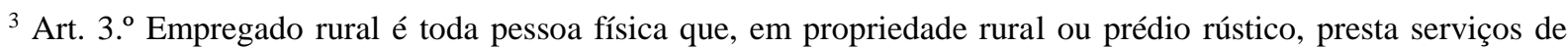
natureza não eventual a empregador rural ou agroindustrial, sob a dependência e subordinação deste e mediante salário ou remuneração de qualquer espécie.

$\S 5 .^{\circ}$ Ao trabalhador rural, residente no local de trabalho, fica assegurado o direito de venda integral das férias regulares, desde que previsto em acordo coletivo ou individual sem prejuízo dos proventos regulamentares de suas férias, mediante concordância do empregador. BRASIL. Câmara Federal. Projeto de Lei No $6442 / 2016$. Disponível em: <http://www.camara.gov.br/proposicoesWeb/prop_mostrarintegra?codteor=1505778>. Acesso em: 28 maio 2017.
} 
o que seria "necessidade imperiosa" ou "motivo de força maior", deixando, novamente, ao critério do empregador ${ }^{4}$.

Do mesmo modo, presume que o descanso semanal poderá ser usufruído de uma única vez, contando que o empregado tenha trabalhado até 18 dias consecutivos 5 .

Outro retrocesso que poderá decorrer se o PL for aprovado envolve a saúde do trabalhador rural, pois a proposta modifica a Norma Reguladora $n^{\circ} 31$, que trata de condições salubres dos empregados, de equipamentos de segurança que garantam a integridade física dos trabalhadores ao cumprimento de normas sanitárias para o uso de defensivos agrícolas e fertilizantes.

Ao final do Projeto, é apresentada a justificativa quanto às alterações anotadas:

As leis brasileiras e, ainda mais, os regulamentos expedidos por órgãos como o Ministério do Trabalho, são elaborados com fundamento nos conhecimentos adquiridos no meio urbano, desprezando usos e costumes e, de forma geral, a cultura do campo.

Dessa forma, além de todas as alterações elencadas, que somadas levam a um enorme retrocesso social, o PL justifica tais modificações, em vista de supostas arbitrariedades do Ministério do Trabalho, afirmando que não se consideram os costumes e a cultura do campo. Argumenta-se como se o trabalhador rural já estivesse acostumado a trabalhar 12 horas por dia, sem descanso semanal, sem receber salário, trabalhando sob permuta de habitação e alimentos.

Nessa seara, é possível fazer uma comparação com os tempos do feudalismo. Naquela época, surgiu a figura dos servos, que nada mais eram do que um tipo de escravo, porém sem a característica de compra/venda. Embora os servos não fossem mais vendidos, eles eram obrigados a passar a vida trabalhando para os senhores feudais, sem remuneração em espécie. Além disso, também não eram donos das terras em que plantavam, pois estas eram emprestadas

\footnotetext{
${ }^{4}$ Art. 7. ${ }^{\circ}$ Admite-se a prorrogação da jornada diária de trabalho por até 4 (quatro) horas ante necessidade imperiosa ou em face de motivo de força maior, causas acidentais, ou ainda para atender a realização ou conclusão de serviços inadiáveis, ou cuja inexecução possa acarretar prejuízos manifestos.

$\S 2 .^{\circ}$ Sempre que o motivo de força maior ou resultante de causas acidentais implicar na interrupção da realização do trabalho, a jornada diária normal poderá ser prorrogada até o limite máximo de 04 (quatro) horas, pelo prazo indispensável à recuperação do tempo perdido e dos trabalhos não realizados no período da interrupção, desde que não exceda de 12 (doze) horas diárias.

${ }^{5}$ Art. 8..$^{\circ}$ Admite-se a execução de trabalho aos domingos e feriados, garantindo-se ao trabalhador, mediante escala de revezamento, repouso semanal remunerado.

§2. ${ }^{\circ}$ A fim de possibilitar melhor convívio familiar e social, o trabalhador rural que desenvolva sua atividade laboral em local distinto de sua residência poderá, mediante solicitação e sujeito à concordância do empregador, usufruir dos descansos semanais remunerados em uma única vez, desde que o período trabalhado consecutivamente não ultrapasse 18 (dezoito) dias.
} 
dos senhores feudais, um tipo de arrendamento, com a diferença de que, ao final, apenas o dono da terra lucraria com a produção.

$\mathrm{Na}$ verdade, a única diferença entre a servidão e a escravidão está apenas no nome, dado que as pessoas continuavam a ser exploradas pelo seu trabalho, sem a dignidade necessária para viverem; saliente-se que a condição de servo era passada de pai para filho, de geração para geração.

Observa-se que, em caso de aprovação, os projetos ora mencionados apenas sancionarão factíveis retrocessos, fazendo com que as pessoas mais humildes, principalmente as do campo, voltem aos tempos de servidão.

Ou seja, se todas essas medidas forem aprovadas, no fundo, ocorrerá, no Brasil, a regularização do trabalho escravo, já que os PL's em discussão se propõem a modificar questões centrais do trabalho que, hoje, compreendem aspectos que versam tão somente pela proteção dos trabalhadores da exploração.

\subsection{A “LISTA SUJA” DO TRABALHO ESCRAVO}

A chamada "lista suja" do trabalho escravo existe desde 2003, com a finalidade de divulgar os nomes de pessoas ou empresas que foram flagradas utilizando condições degradantes de trabalho e vida em seus produtos e serviços. Apesar do serviço denunciante desta relação, em 2014, o Ministro do STF Ricardo Lewandowsk suspendeu referido inventário, em caráter liminar, devido ao pedido de uma associação de incorporadoras. Em maio de 2016, contudo, atendendo à decisão da Ministra Carmem Lúcia, dita suspensão foi revogada e deuse, então, início a uma disputa judicial entre o Ministério Público do Trabalho (MPT) e Governo Federal quanto ao tema.

Após, a lista apenas voltou a ser editada em 23 de março de 2017, por meio do site do Ministério do Trabalho e Emprego. Primeiramente, constou com 85 nomes que foram flagrados explorando trabalho escravo; mas, no mesmo dia e apenas duas horas depois de sua divulgação, foram retirados 17 (SAKAMOTO; WROBLESKI, 2017).

Entretanto, em uma reviravolta inesperada, em 16 de outubro de 2017 foi publicada uma nova portaria (1129/2017) que redefinia o conceito de trabalho escravo contemporâneo no Brasil. Tal medida foi duramente questionada por diversos órgãos públicos como Ministério Público do Trabalho, Procuradoria Geral da República, ONU e OIT, assim como diversas 
entidades que defendem trabalhadores. Por conta da repercussão negativa, tal portaria foi revogada em 29 de dezembro de 2017 sendo retirados todos os pontos de retrocessos.

Outra preocupante atitude por parte do Governo Federal foi a descoberta de que fazendeiros condenados por se beneficiarem com a prática de escravidão conseguiram empréstimos junto ao BNDES (Banco Nacional de Desenvolvimento Econômico e Social), o que é expressamente proibido, de acordo com o art. $1^{\circ}$ da Resolução ${ }^{\circ} 3.876 / 2010$ do Conselho Monetário Nacional ${ }^{6}$.

É importante lembrar que a utilização de dinheiro público para financiamento de pessoas ou empresas flagradas aliciando trabalhadores em situação análoga à de escravidão é algo gravíssimo e compromete a idoneidade de instituições públicas. Nesse sentindo, é preciso que sejam fornecidos esclarecimentos necessários à sociedade, pois não é ético que o Estado proteja interesses privados e corporativistas, deixando hipossuficientes ao capricho de exploradores.

A "lista suja" foi criada com o intuito de punir empregadores flagrados explorando trabalhadores na condição análoga à de escravo, servindo de exemplo, para que o restante da população assimile que situações de escravidão contemporânea não serão toleradas pela Justiça. Logo, é de extrema relevância que o seu verdadeiro objetivo não seja distorcido.

\section{PROPOSTAS}

Mediante as informações colhidas e elencadas neste artigo, torna-se possível afirmar que, efetivamente, as melhorias de trabalho para as pessoas que vivem em situação semelhante ao trabalho escravo, como por exemplo, os madeireiros, objeto deste artigo, somente serão possíveis com maior atuação do Estado, que, por sua vez, pode acontecer com as seguintes medidas:

1) Incentivos, através de políticas públicas, para maior desenvolvimento econômico nas regiões mais afetadas, sem que isso cause retrocessos sociais graves como aqueles que estão sendo pretendidos com os projetos de leis ora analisados;

\footnotetext{
${ }^{6}$ Art. $1^{\circ}$ Fica vedada às instituições financeiras integrantes do Sistema Nacional de Crédito Rural (SNCR) a contratação ou renovação, ao amparo de recursos de qualquer fonte, de operação de crédito rural, inclusive a prestação de garantias, bem como a operação de arrendamento mercantil no segmento rural, a pessoas físicas e jurídicas inscritas no Cadastro de Empregadores que mantiveram trabalhadores em condições análogas à de escravo instituído pelo Ministério do Trabalho e Emprego, em razão de decisão administrativa final relativa ao auto de infração. BANCO CENTRAL DO BRASIL. Resolução $\mathbf{n}^{\mathbf{0}}$ 3876/2010. Disponível em: <http://www.bcb.gov.br/pre/normativos/res/2010/pdf/res_3876_v1_O.pdf〉. Acesso em: 17 maio 2017.
} 
2) Qualificação de mão de obra, considerando as pessoas resgatadas em tais circunstâncias, e, principalmente, a oferta de melhores empregos, fato que está atrelado, diretamente, ao desenvolvimento econômico;

3) Maior fiscalização tanto por parte do Governo Federal, dos governos Estaduais e Municipais, com contratação de fiscais, manutenção de equipamentos, de veículos e aprovisionamento de todo o aparato policial necessário;

4) Maior investimento em infraestrutura, como telecomunicação, nas regiões onde há maior número de pessoas resgatadas a fim de possibilitar maior comunicabilidade entre os locais com o objetivo de colher denúncias e punir os responsáveis, e;

5) Por meio da transparência das empresas na divulgação da origem de seus produtos, a sociedade poderá certificar-se de que aquilo que consome não é fruto de trabalho escravo. Isso seria viável com legislação mais rígida, que oportunizasse, inclusive, incentivos fiscais, beneficiando os empregadores que não ferem normas trabalhistas, tampouco humanitárias.

Portanto com o desenvolvimento econômico e a qualificação das pessoas nessas regiões de conflito, vislumbra-se um cenário com maior distribuição de renda e proteção ao hipossuficiente, a fim de reduzir sua vulnerabilidade e garantir os direitos da personalidade neste ambiente de trabalho.

\section{CONCLUSÕES}

Após a análise empreendida, baseada em documentos oficiais, referências bibliográficas e reportagens investigativas, pôde-se observar que a questão do trabalho escravo contemporâneo ainda é algo de difícil solução. Basta considerar que, mesmo ciente da emergência em tratar o problema, o Brasil ignorou-o por 25 anos, retardando drasticamente o olhar governamental e demonstrando extremo descaso com os trabalhadores imersos nesse universo.

Atualmente, a legislação é considerada moderna, no entanto, o país regrediu na esfera das garantias legais. Apesar de o Brasil ter abolido a escravidão há quase 130 anos, semelhante situação de outrora se perpetua por motivos diversos, mormente pela escassez de oportunidades, insuficiência de melhores empregos e ampla privação de condições de vida digna. $O$ fato tem ocorrido, notadamente, no campo, explorando pessoas humildes, que não possuem o mínimo para a sobrevivência.

Nesse contexto, o trabalhador em situação de escravidão é privado de sua liberdade e tratado como coisa, ocorrendo violação aos seus direitos da personalidade, mediante desobediência aos seus direitos básicos, sendo o direito ao trabalho decente um deles, inclusive. 
Ainda, no que se refere ao trabalho escravo dos trabalhadores madeireiros, um dos grandes problemas encontrados, tanto por órgãos oficiais, como por ONG's, é o controle dessa ilegalidade. Uma vez que os empregadores usam "laranjas" para misturarem a madeira ilegal com madeira legal, torna-se praticamente impossível rastrear o produto derivado do trabalho escravo. Além disso, foi identificado que diversas marcas, brasileiras e estrangeiras, utilizam madeira ilegal em seus produtos, o que culmina no financiamento da prática escravagista no país.

Percebe-se que o problema da escravidão contemporânea também passa pela seara política, com o Congresso Nacional mais comprometido com interesses pessoais e empresariais. Conforme análises decorrentes dos Projetos de Lei no 432/2013 e 6442/2016 e da Medida Provisória $\mathrm{n}^{\mathrm{0}} 759 / 2016$, permitiu-se deduzir que o trabalhador rural ficará ao sabor da própria sorte e, então, situações de trabalho escravo apenas tendem a aumentar. Consequentemente, caso referidos projetos sejam aprovados, todas as medidas adotadas até hoje para combater o trabalho escravo contemporâneo, as quais são reconhecidas internacionalmente, constituindo uma das legislações mais modernas sobre o tema, serão revogadas e cairão em desuso.

Evidente que tal probabilidade é algo que causa imensa preocupação; da mesma forma que o PL no 432/2013 tornar-se-ia uma legislação simbólica. O mesmo ocorreria com a Lei de Reforma Agrária, que, com todos esses impedimentos, jamais sairá do papel para o campo, tornando-se apenas uma legislação sem efeitos práticos. Vale ainda destacar que a legislação em trâmite pretende criar também um mercado imobiliário por meio de terras nacionais.

Além disso, não houve diálogo com os principais interessados, nem mesmo com o Ministério Público, ou com movimentos sociais ligados à questão, como a Pastoral da Terra, que é uma organização não governamental atuante no combate à escravidão moderna, bem como quanto a reforma agrária. É preciso que seja feita uma análise profunda sobre essa nova lei para que a população mais carente não seja prejudicada de forma irreversível.

Apesar de o país ter sido reconhecido internacionalmente pela criação da "lista suja" do trabalho escravo, existem evidências de que há um movimento contrário à sua divulgação, não fosse assim, mencionada relação de empregadores infratores não teria ficado suspensa por, aproximadamente, três anos, pois foi retirada para consulta pública em 2014 e apenas voltou a ser divulgada no início de 2017, após uma batalha judicial entre Governo Federal e Ministério Púbico do Trabalho. 
É impreterível a inclusão de políticas públicas e leis que visem à punição dos responsáveis, englobando as serrarias - nos confins das florestas - às grandes multinacionais que se beneficiam, contribuem e financiam com a prática ilegal.

É imperioso que os trabalhadores resgatados tenham o mínimo de dignidade para sobrevivência, pois, dada a miséria em que vivem, acabam sendo obrigados a retornar para os mesmos locais onde foram explorados. Essa perspectiva se modificaria com a qualificação profissional e o desenvolvimento da região, e da conscientização em preservar a natureza.

É necessário olhar para essas pessoas que têm os seus direitos sistematicamente violados, caso contrário, o Brasil regredirá no plano das garantias legais e seguirá na contramão mundial, no que se refere aos direitos humanos e do trabalho em um sistema considerado democrático. Afinal, um dos princípios basilares de uma sociedade com essa natureza está, justamente, na liberdade que seus cidadãos podem usufruir e na garantia de seus direitos fundamentais.

\section{REFERÊNCIAS}

ARANHA, Ana; DIAZ, João Cesar. Leis não barram produtos fabricados com trabalho escravo. Repórter Brasil. 2017. Disponível em: <http://reporterbrasil.org.br/2017/03/leis-nao-barramprodutos-fabricados-com-trabalho-escravo/>. Acesso em: 25 maio 2017.

BANCO CENTRAL DO BRASIL. Resolução $\mathbf{n}^{\mathbf{0}}$ 3876/2010. Disponível em: <http://www.bcb.gov.br/pre/normativos/res/2010/pdf/res_3876_v1_O.pdf>. Acesso em: 17 maio 2017.

BRASIL. Código Penal. Decreto-Lei no 2.848, de 07 de dezembro de 1940. Disponível em: <http://www.planalto.gov.br/ccivil_03/decreto-lei/Del2848compilado.htm>. Acesso em: 26 maio 2017.

Ministério do trabalho e emprego. Manual de combate ao trabalho em condições
análogas à a de escravo. $2011 . \quad$ Disponível 20 em:
<http://acesso.mte.gov.br/data/files/8A7C816A350AC88201350B7404E56553/combate\%20tr
abalho\%20escravo\%20WEB.PDF>. Acesso em: 25 maio 2017.

Constituição Federal. Diário Oficial da União. Disponível em: <http://www.planalto.gov.br/ccivil_03/constituicao/constituicao.htm>. Acesso em: 12 maio 2017.

Câmara Federal. Projeto de Lei $\mathbf{N}^{\mathbf{0}}$ 6442/2016. Disponível em: <http://www.camara.gov.br/proposicoesWeb/prop_mostrarintegra?codteor=1505778>. Acesso em: 28 maio 2017. 
BRITO FILHO, José Cláudio Monteiro. Trabalho escravo caracterização jurídica. 2. ed. São Paulo: LTr, 2017.

CAMPELO, Lilian. Brasil de Fato. MP 759 expropria a população pobre do campo, explica Sérgio Sauer, 25 de maio de 2017. Disponível em: $<$ https://www.brasildefato.com.br/2017/05/25/mp-759-expropria-a-populacao-pobre-docampo-explica-sergio-sauer/>. Acesso em: 28 de maio de 2017.

CAMPOS, André. Tramontina comprou madeira de serraria flagrada com trabalho escravo. 2017. Repórter Brasil. Disponível em: <http://reporterbrasil.org.br/2017/03/tramontinacomprou-madeira-de-serraria-flagrada-com-trabalho-escravo/> . Acesso em: 22 maio 2017.

CORTEZ, Juliano Chaves. Trabalho escravo no contrato de emprego e os direitos fundamentais. 2 ed. São Paulo: LTr, 2015.

DELGADO, Mauricio Godinho. Princípios de direito individual e coletivo do trabalho. 4 ed. São Paulo: LTr, 2013.

FIORILLO, Celso Antonio Pacheco. Princípios do direito processual ambiental. 5 ed. São Paulo: Saraiva, 2012.

2013.

; CONTE, Christiany Pegorari. Crimes no meio ambiente digital. São Paulo: Saraiva,

GALHARDO, Ricardo; FARIA, Thiago. Temer calcula ter R \$ 30 bi para aprovar Previdência. Estadão. 2018. Disponível em: <http://politica.estadao.com.br/noticias/geral,temer-calculater-r-30-bi-para-aprovar-previdencia,70002156618>. Acesso em: 26 de jan de 2018.

GAGLIANO, Pablo Stolze; PAMPLONA FILHO, Rodolfo. Novo curso de direito civil: parte geral. 15. ed. São Paulo: Saraiva, 2013.

LOTTO, Luciana Aparecida. Ação civil pública trabalhista contra o trabalho escravo no brasil. 2 ed. São Paulo: LTr, 2015.

MEDEIROS, Étore; FONSECA Bruno. As bancadas da câmara. Publica. 2016. Disponível em: <http://apublica.org/2016/02/truco-as-bancadas-da-camara/>. Acesso em: 27 maio 2017.

, Benizete Ramos de; HAZZAN, Ellen. Trabalho, castigo e escravidão passado ou futuro? São Paulo: LTr, 2017.

ONUBR. Nações Unidas no Brasil. ONU manifesta preocupação com projeto de lei que altera conceito de trabalho escravo no Brasil. 2016. Disponível em: <https://nacoesunidas.org/onumanifesta-preocupacao-com-projeto-de-lei-que-altera-conceito-de-trabalho-escravo-nobrasil/>. Acesso em: 24 maio 2017.

PALO NETO, Vito. Conceito jurídico e combate ao trabalho escravo contemporâneo. São Paulo: LT, 2008. 
SAKAMOTO, Leonardo; WROBLESKI, Stefano. Governo oculta nomes que poderiam estar na "lista suja" do trabalho escravo. Repórter Brasil. 2017. Disponível em: $<$ http://reporterbrasil.org.br/2017/03/governo-oculta-nomes-que-poderiam-estar-na-lista-sujado-trabalho-escravo/>. Acesso em: 15 maio 2017.

SAKAMOTO, Leonardo. Operação contra trabalho escravo é cancelada por falta de passagem aérea. Blog do Sakamoto. 2018. Disponível em: $<$ https://blogdosakamoto.blogosfera.uol.com.br/2018/01/27/operacao-contra-trabalhoescravo-e-cancelada-por-falta-de-passagem-aerea/>. Acesso em: 28 de jan de 2018.

SCHWARZ, Rodrigo Garcia. Terra de trabalho, terra de negócio. O trabalho escravo contemporâneo na perspectiva (da violação) dos direitos sociais. São Paulo: LTr, 2014.

SILVA, Leda Maria Messias; PEREIRA, Marice Taques. Docência (In)digna: meio ambiente laboral do professor e as consequências em seus direitos da personalidade. São Paulo: LTr, 2013.

SUZUKI, Natália; CASTELI, Thiago. Trabalho escravo é ainda uma realidade no Brasil. Carta Educação. 2016. Disponível em: <http://www.cartaeducacao.com.br/aulas/fundamental2/trabalho-escravo-e-ainda-uma-realidade-no-brasil/>. Acesso em: 22 maio 2017.

O TRABALHO escravo no Brasil. Repórter Brasil. Disponível em: <http://escravonempensar.org.br/sobre-o-projeto/o-trabalho-escravo-no-brasil/>. Acesso em: 20 maio 2017. 